\title{
PENERAPAN SHAPING GUNA MEMBENTUK PERILAKU BEKERJASAMA GOSOK GIGI PADA ANAK PENYANDANG SEVERE INTELLECTUAL DISABILITIES
}

\author{
${ }^{1}$ Sanny Novelty Singarimbun dan ${ }^{2}$ Woro Kurnianingrum \\ ${ }^{1}$ Fakultas Psikologi, Universitas Tarumanagara Jakarta \\ Email: sanny.novelty@ gmail.com \\ ${ }^{2}$ Fakultas Psikologi, Universitas Tarumanagara Jakarta
}

\begin{abstract}
ABSTRAK
Perawatan kesehatan terutama pada anak dengan intellectual disabilities yang berat diperlukan terutama pada kesehatan gigi. Oleh karena itu studi ini mengenai bagaimana dapat meningkatkan perilaku kerjasama pada anak dengan intellectual disabilities kategori berat dengan pengasuhnya. Metode yang digunakan single subject design. Jumlah partisipan adalah 1 orang, berjenis kelamin perempuan, dan berusia 9 tahun. Hasilnya menunjukkan bahwa anak berhasil, anak mampu untuk menunjukkan perilaku bekerjasama berupa mengikuti instruksi dan bersedia digosok giginya oleh pengasuh. Perlu memperhatikan pada kemampuan pengasuh dalam mendampingi dan kesadaran pengasuh akan pentingnya perawatan gigi. Bagi anak, diperlukan penguat untuk dapat memahami tindakannya sudah tepat.
\end{abstract}

Kata Kunci: intellectual disability, tingkat keparahan severe, shaping, gosok gigi, perilaku bekerjasama

\section{PENDAHULUAN}

\section{Latar Belakang}

Penanganan terhadap anak intellectual disability dengan tingkat keparahan berat masih jarang dilakukan di Indonesia; penanganan biasanya terfokus pada individu dengan tingkat keparahan yang ringan dan sedang (Kusharyani \& Kurnianingrum, 2017; Purwandari, 2015). Kondisi ini yang pada akhirunya memacu peneliti untuk membahas tema anak intellectual disability dengan tingkat keparahan yang berat atau severe. Kondisi anak yang mengalami intellectual disability kategori berat ditandai dengan ketidakpahaman dalam makna kata, umumnya hanya mengetahui satu atau dua kata baik pengucapan maupun perbendaharaan kata, perlu mendapatkan pendampingan terus menerus dari pengasuh

Kondisi intellectual disability yang tidak mendapatkan penanganan yang tepat dari lingkungan dan kurangnya stimulus yang diberikan akan meningkatkan keparahan dari intellectual disability (Supriyono, 2012). Kondisi ini sama halnya dengan perawatan kesehatan, diperlukan kesadaran dari pengasuh untuk menyadari akan pentingnya menjaga kesehatan dari anak penyandang disability kategori berat ini.

Perawatan kesehatan dapat berupa perawatan gigi (Feldberg \& Merrick, 2014; Waldron et al., 2017). Kondisi ini penting karena tempat pertama kali makanan masuk ke dalam tubuh adalah mulut (Moore, Shiers, Daly, Mitchel \& Gaughran, 2015; Gabre et al., 2001).Selain itu, dampak yang disebabkan oleh kurangnya perawatan gigi akan mempengaruhi fungsi pencernaan, penyakit mulut, dan gangguan otot (Anders \& Davis, 2010; Ummer-Christian et al., 2018)

Pentingnya menjaga kesehatan tersebut menunjukkan bahwa anak dengan intellectual disability kategori berat memerlukan perawatan kesehatan gigi, karena kesejahteraan terhadap keberlangsungan hidup dari anak tersebut dan orang-orang ada di sekitarnya perlu diperhatikan (Crnic, Mclntyre, Neece, \& Blacher, 2017). Bagi anak-anak yang mengalami severe intellectual disability diperlukan penanganan yang memperhatikan penggunaan komunikasi yang dilakukan 
sepanjang intervensi tersebut diberikan. Hal tersebut akan mempengaruhi keberhasilan dari suatu treatment yang diberikan (Snell et al., 2010).

Studi ini mempelajari mengenai metode yang dapat digunakan dalam menerapkan perilaku bekerjasama pada anak dengan intellectual disability dalam kategori berat sehingga anak mampu memaksimalkan kebersihan dirinya dengan menunjukkan perilaku bekerjasama membantu dan mengikuti arahan pengasuh. Rumusan masalah dalam penelitian ini adalah Efektivitas penerapan shaping pada pembentukan perilaku bekerjasama gosok gigi pada anak penyandang severe intellectual disability. Tujuan dalam penelitian ini adalah meningkatkan perilaku bekerjasama untuk digosokkan giginya oleh pengasuh sehingga membantu merawat kesehatan gigi anak.

\section{METODE PENELITIAN}

\section{Partisipan}

Penelitian ini melibatkan satu individu yang mengalami gejala severe intellectual disability. Partisipan akan menggunakan intervensi modifikasi perilaku dengan shaping. Tujuannya untuk membentuk kerjasama pada kegiatan gosok gigi yang dilakukan oleh pengasuh. Sebelumnya, partisipan mengalami kesulitan untuk bekerjasama untuk digosokkan giginya oleh pengasuh. Kondisi severe intellectual disability menurut DSM V ditandai dengan (a) keterampilan konseptual yang terbatas, (b) kemampuan bahasa verbal terbatas pada satu atau dua kata dan berdasar atas kondisinya saat ini, dan (c) individu yang membutuhkan bantuan untuk semua aktivitas kesehariannya (APA, 2013). Partisipan sulit berbicara dengan orang lain, tetapi mampu membaca bahasa non verbal dan menanggapinya stimulus non verbal dan memerlukan bantuan dan pengarahan langsung terhadap perilaku yang diharapkan. Partisipan penelitian belum mampu merawat dirinya sendiri, perlu pendampingan dari pengasuh untuk tugas keseharian seperti mandi, berpakaian, buang air besar dan kecil, serta diperlukan pengawasan supaya tidak menyakiti diri sendiri dan orang lain. Usia partisipan penelitian saat ini adalah 9 tahun.

\section{Persiapan dan prosedur penelitian}

Tahapan pertama ini, peneliti meminta izin kepada pengasuh untuk melakukan penelitian terhadap anak yang diduga mengalami severe intellectual disability. Kemudian peneliti meminta pengasuh mengisi lembar informed consent yang menyatakan adanya kesediaan pengasuh mengizinkan peneliti melakukan penelitian ini. Setelah mendapatkan izin dari pengasuh, peneliti mulai melakukan wawancara kepada pengasuh mengenai kondisi partisipan saat ini dan latar belakang keluarga partisipan. Selanjutnya, peneliti mulai melakukan observasi terhadap perilaku partisipan. Proses observasi ini dilakukan dengan mengacu pada panduan dari List of Behavior Cues (Sattler, 1990). Tahap berikutnya, peneliti pertama menggunakan beberapa alat tes psikologi dan beberapa jurnal pendukung untuk memperkuat dugaan dan landasan dalam menentukan perilaku partisipan.

Alat tes psikologi yang digunakan oleh peneliti adalah Stanford Binet, DDST, Vineland Social Maturity Scale (VSMS) dan Short Sensory, dan beberapa tes informal lainnya seperti berlari, menyapa, menunjukkan makanan yang bisa dimakan dan tidak dimakan, dan menentukan benda yang sama.

Setelah penegakan diagnosa, peneliti mulai mengobservasi kebutuhan yang diperlukan oleh partisipan penelitian. Hasilnya menunjukkan bahwa partisipan, memiliki kesulitan untuk bekerja sama dengan pengasuh untuk digosok giginya. Akibatnya, partisipan sering berdarah saat giginya digosok oleh pengasuh. Oleh karena itu, peneliti menentukan partisipan sebagai target dalam penelitian ini. 


\section{Desain penelitian}

Penelitian ini dilakukan dengan desain single-subject design, yang bertujuan untuk memberikan intervensi kepada satu partisipan. Tujuannya, memastikan bahwa intervensi dapat sesuai dengan tujuan dan harapan. Selain itu, memudahkan dalam menangani permasalahan yang dihadapi oleh partisipan yakni kesulitan untuk bekerjasama dengan pengasuh untuk digosok giginya. Hal ini diperlukan karena akan berdampak pada luka yang berkelanjutan pada gigi, gigi tidak bersih sehingga menimbulkan penyakit, dan gigi yang patah. Pemberian treatment akan dilakukan setiap hari selama 15 sesi, di mana waktu intervensi selama 60-120 menit untuk memastikan bahwa partisipan memahami metode belajar kepada partisipan. Proses yang dilalui dengan adanya pemberian prompting dan reinforcement sepanjang intervensi untuk menunjukkan bahwa partisipan sudah melakukan yang benar. Monitoring akan dilakukan setelah 2 minggu dan memberikan pelatihan metode reinforcement dan prompting yang diberikan kepada pengasuh. Selanjutnya akan dilakukan evaluasi pengukuran selama 2 sesi. Teknik pengukuran yang dilakukan adalah latency, teknik modifikasi perilaku adalah shaping, reinforcement yang diberikan adalah social berupa jalan keliling panti, dipeluk, dipuji dan diberikan senyuman. Jika partisipan mulai menggigit dirinya pada saat diberikan intervensi diucapkan kata tidak, jika berhasil diberi senyuman, diberitahu bagus berulang kali dan dipeluk.

\section{Setting lokasi}

Penelitian akan dilakukan di Panti Sosial X dengan alasan partisipan akan sulit untuk dibawa ke Universitas Tarumanagara untuk diberikan penanganan. Sebelum memulai sesi, peneliti akan mengajak partisipan jalan keliling panti. Proses intervensi akan dilakukan di taman, tempat biasanya partisipan dan warga binaan lainnya sikat gigi. Tujuan kegiatan ini agar partisipan menyadari lokasi dan kegiatan yang harusnya dilakukan selama kegiatan gosok gigi.

\section{Perlengkapan penelitian}

Selama melakukan penelitian, peneliti memerlukan lembar biodata, lembar informed consent, DDST, perlengkapan alat tes Stanford Binet, VSMS, kertas bergambar yang memiliki dua kartu yang sama, short sensory, peralatan penguji sensori (garam, gula, cabe, kulit kerang, squishy, papan keseimbangan, dan tangga), sikat gigi silikon, sikat gigi bulu halus, sikat gigi reguler, dan odol tidak memiliki kandungan detergen dan beraroma strawberry. Penggunaan odol tanpa detergen untuk menghindari partisipan menolak digosok giginya karena rasa detergen yang terlalu kuat dilidah yang dapat menyebabkan partisipan akan menolak rasanya karena terdapat rasa mint yang terlalu kuat.

\section{Pengukuran}

Sebelum intervensi, partisipan akan dicoba untuk digosok giginya dengan sikat gigi reguler, sikat gigi bulu halus dan sikat gigi silikon. Selama partisipan diberikan sikat gigi reguler, sikat gigi bulu halus, sikat gigi silikon untuk diketahui kenyamanan partisipan untuk gosok gigi. Berdasarkan hasil dari tipe sikat gigi yang digunakan diketahui bahwa partisipan lebih mudah menggunakan sikat gigi bulu halus dan silikon.

\section{HASIL DAN PEMBAHASAN}

\section{Gambaran partisipan}

Secara umum, partisipan memiliki usia mental setara 1 tahun 6 bulan, memiliki kemampuan berbahasa setara usia 10 bulan, memiliki kemampuan motorik kasar setara usia 16 bulan, kemampuan motorik halus setara 5 bulan dan kemampuan personal sosial setara usia 10 bulan, 
dan memiiki masalah pada oral dan perabaannya. Selain itu, hal ini yang menyebabkan partisipan kesulitan untuk menggunakan sikat gigi reguler. Kondisi lainnya menunjukkan bahwa partisipan terkadang makan makanan kotorannya sendiri, tidak dapat menyadari sedang buang air besar atau buang air kecil, mandi masih perlu didampingi, berpakaian masih perlu diarahkan dan dibantu, tidak dapat mengikuti instruksi, perlu ada pengulangan arahan berupa tindakan langsung untuk mengarahkan perilakunya, belum mampu untuk menaiki dan menuruni tangga sendiri (perlu pendampingan), menyentuh benda dengan menciumnya dan memainkannya dengan tangan, belum bisa diminta untuk digosok giginya oleh pengasuh, dan memiiki giginya yang berwarna kuning dan beberapa sudah berlubang.

\section{Pelaksanaan intervensi}

Intervensi dilakukan secara berkelanjutan setiap hari pada pagi hari dan di tempat yang sama, biasanya dilakukan kegiatan sikat gigi. Kegiatan ini akan dilakukan secara konsisten setiap kehadiran pada sesi pertemuan. Pengetesan dilakukan dengan mengecek kemampuan partisipan mengikuti kegiatan gosok gigi. Kegiatan baseline ini dilakukan selama 3 (tiga) kali. Sebelum tahap baseline dilakukan, beberapa kali peneliti melakukan tes penggunaan odol yang akan digunakan dalam kegiatan intervensi.

Proses intervensi dilakukan pertama kali dengan cara mendudukkan partisipan di pangkuan peneliti kemudian peneliti memulai proses intervensi yang dilakukan. Setelah itu evaluasi diberikan setiap kali sesi berhasil dijalankan dengan mengucapkan 'terima kasih' kepada partisipan. Selanjutnya peneliti memberitahukan bahwa partisipan sudah melakukan yang bagus hari ini dan memberikan tepuk tangan. Kemudian peneliti akan mengajak partisipan untuk jalan keliling panti jika partisipan berhasil melewati setiap sesi yang diberikan. Pada setiap sesi, peneliti akan memberikan arahan kepada partisipan untuk menggosok gigi. Kegiatan diawali dengan membuka mulut melalui prompting lisan dan gestur melalui menunjukkan mulutnya untuk dibuka dan memperagakan membuka mulut. Ketika berhasil diberikan pelukan dan diberitahu 'bagus'. Durasi yang dilakukan selama 60-120 menit, tergantung kondisi partisipan kala itu. Sesi yang dirancang sebanyak 15 sesi dimulai dengan mengenalkan sikat gigi dan pasta gigi yang digunakan hingga kegiatan menggosokkan gigi dengan sikat gigi sesuai dengan tahapan usianya. Setiap sesi dilakukan secara berkelanjutan setiap hari, berkaitan dengan proses belajar yang berkelanjutan.

\section{Hasil intervensi}

Berdasarkan hasil intervensi, digambarkan bahwa partisipan mampu melakukan kegiatan sikat gigi tetapi diperlukan latihan yang berulang untuk mampu untuk melakukan kegiatan tersebut. Jika di awal partisipan menolak, namun seiring berjalannya waktu dan latihan yang berulang, partisipan mampu untuk melakukan kegiatan kerjasama untuk menggosok giginya. Kegiatan tersebut dilakukan berulang agar partisipan mengetahui keberhasilan partisipan dalam menyelesaikan tugas yang diberikan oeh peneliti. Berikut ini keberhasilan dalam intervensi dari 20 kali percobaan.

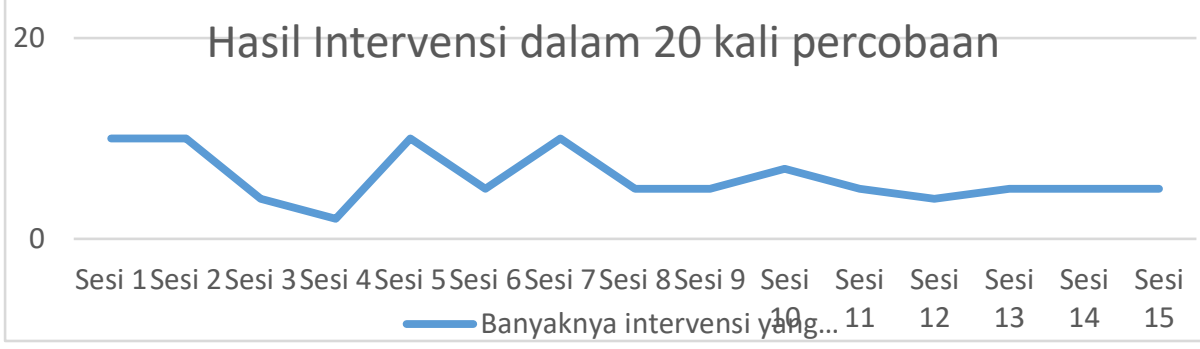

Figur 1. Grafik hasil intervensi dalam 20 kali percobaan 


\section{KESIMPULAN DAN SARAN}

Berdasarkan hasil evaluasi ditemukan adanya pembentukan perilaku bekerjasama untuk digosok giginya oleh pengasuh. Partisipan menjadi lebih mudah melakukan kegiatan bersama dalam gosok gigi meskipun perlu dilakukan berulang kali. Namun menggosok gigi tersebut perlu diberikan prompting secara verbal, gestur, dan non verbal. Selain itu, perlu ada penguat yang diberikan berulangkali atas tindakan yang dilakukan baik hal tersebut benar atau salah untuk membantu partisipan mengetahui tindakannya. Jika sebelumnya, partisipan tidak bersedia untuk mengikuti instruksi dalam gosok gigi yang diberikan oleh pengasuh, perlahan partisipan bersedia untuk mengikuti kegiatan gosok gigi tersebut.

\section{Diskusi}

Pentingnya memperhatikan metode komunikasi yang digunakan dalam kegiatan intervensi perlu diperhatikan (Snell et al., 2010; Brady et al., 2016) menunjukkan bahwa komunikasi adalah hal yang terpenting pada intervensi anak intellectual disability dengan tingkat keparahan yang berat. Kondisi yang muncul pada anak ID ini adalah ketidakmampuan untuk mengetahui tindakan yang dilakukannya sudah tepat atau tidak, sehingga diperlukan komunikasi berkelanjutan mengenai apa yang sudah dilakukannnya. Selain itu, pengasuhnya perlu diberikan pendampingan bagaimana mempertahankan komunikasi yang dilakukan secara berulang kepada anak-anak intellectual disability dengan tingkat keparahan yang berat. Hal tersebut dikarenakan individu yang memiliki tingkat keparahan yang berat cenderung tidak memahami tindakannya sehingga peran pengasuhan adalah membantu anak tersebut menyadari tindakannya dengan menggunakan bahasa yang sederhana yang mudah dimengeri dan dipahami oleh anak-anak berkebutuhan tersebut. Perihal lainnya yang perlu diperhatikan adalah penguat yang diberikan pada setiap intervensi yang dilakukan sangatlah penting, karena penguat tersebut akan membantu partisipan dalam melaksanakan intervensi dan tujuan dari kegiatan tersebut dapat berjalan dengan tepat.

Selain itu, penting untuk memperhatikan kebutuhan anak saat itu, apa yang menjadi kebutuhannya terhadap penggunaan sikat gigi maupun pasta gigi atau odol yang digunakan. Hal tersebut dikarenakan terdapat kemungkinan bahwa anak dengan intellectual disability tersebut memiliki masalah dengan fungsi oralnya sehingga ia merasa sakit jika dipaksakan menggunakan sikat gigi ataupun pasta gigi yang digunakannya.

Apabila penelitian dilakukan serupa, dapat dilakukan dengan menggunakan metode duduk sendiri tetapi tetap diperlukan pendampingan oleh pengasuh. Tujuannya adalah untuk mengetahui tingkat keberhasilan anak dengan tingkat intellectual disability kategori berat dalam melaksanakan kegiatan menggosok gigi dan meningkatkan gerakan tubuhnya yang melibatkan tangan dan otot mulut.

Ucapan Terima Kasih (Acknowledgement)

Peneliti mengucapkan terima kasih kepada seluruh pihak yang sudah bersedia berpartisipasi dalam penelitian kali ini.

\section{REFERENSI}

Anders, P. \& Davis, E.L. (2010). Oral health of patients with intellectual disabilities: A systematic review. Special Care in Dentistry, 30(3), 110-117.

Brady, N.C, Bruce, S., Goldman, A., Erickson, K., Mineo, B., Ogletree, B.T., Paul, D., Romski, M.A., Sevcik, R., Siegel, E., Schoonover, J., Snell, M., Sylvester, L., \& Wilkinson, K. (2016). Communication services and supports for individuals with severe disabilities 
guidance for assessment and intervention. Am Journal Intellectual Developmental Disability, 121(2), 121-138

Crnic, K.A., Mclntyre, L.L., Neece, C.L., \& Blacher, J. Intellectual disability and developmental risk: Promoting intervention to improve child and family well being. Child Development, $88(2), 436-445$.

Feldberg, I., \& Merrick, J. (2014). Intellectual disability and dental services: experience from israel. Frontier in Public Health, 133 (2), 1-3. doi: 10.3389/fpubh.2014.00133

Kusharyani, F., \& Kurnianingrum, Woro. (2017). Penerapan total task presentation dalam meningkatkan kemampuan mengosok gigi pada anak moderate intellectual disability. Jurnal Muara Ilmu Sosial, Humaniora, dan Seni, 1(2), 32-40

Moore, S., Shiers, D., Daly, B., Mitchel, A.J., \& Gaughran, F. (2015). Promoting physical health for people with schizophrenia by reducing disparties in medical and dental care. Acta Psychiatrica Scandinavia, 132 (2), 109-121.

Purwandari, E. (2015). Pengembangan instrumen asesmen perilaku adaptif bagi remaja dengan intellectual disability [S2 thesis]. Universitas Pendidikan Indonesia, Bandung.

Sattler, J.M. (1990). Assessment of Children. ( $3^{\text {rd }}$ ed.). San Diego: Jerome M. Sattler Publisher.

Snell, M.E., Brady, N., Mclean, L., Ogletree, B.T., Siegel, E., Sylvester, L., Mollica, B.M., Paul, D., Romski, M.A., \& Sevcik, R. (2010). Twenty years of communication intellectual and developmental disabilities. Am Journal Development Disability, 115(5), 364-380. doi:10.1352/1944-7558-115-5.364

Ummer-Christian, R., Iacono, T., Grils, N., Pradhan, A., Hughes, N., \& Gussy, M. Access to dental services for children with intellectual and developmental disabilities - A scoping review. Research in Developmental Disabiities, 74, 1-13.

Waldron, C., Phadraig, C.M., Nunn, J., Comiskey, C., Donnelly-Swift, E., Guerin, S., \& Clarke, M.J. (2017). Oral hygiene programmes for people with intellectual disabilites. Cochrane Database of Systematic Reviews, 4. doi: 10.1002/14651858.CD012628 